\title{
Article \\ Structure and Characterization of TiC/GLC Multilayered Films with Various Bilayers Periods
}

\author{
Weiqi Wang ${ }^{1}$, Xiaoming Ling ${ }^{1, *}$, Rui Wang ${ }^{1,2}$, Wenhao $\mathrm{Nie}^{1,2}, \mathrm{Li} \mathrm{Ji}^{3}$ and Hongxuan $\mathrm{Li}^{3, *}$ \\ 1 National Engineering Research Center for Technology and Equipment of Green Coating, \\ Lanzhou Jiaotong University, Lanzhou 730070, China; wangwq90@lzjtu.edu.cn (W.W.); \\ lzjtwr@163.com (R.W.); niewenhao202106@163.com (W.N.) \\ 2 Key Laboratory of Opto-Electronic Technology and Intelligent Control, Lanzhou Jiaotong University, \\ Ministry of Education, Lanzhou 730070, China \\ 3 State Key Laboratory of Solid Lubrication, Lanzhou Institute of Chemical Physics, \\ Chinese Academy of Sciences, Lanzhou 730000, China; jili@licp.cas.cn \\ * Correspondence: lingxm24@mail.lzjtu.cn (X.L.); lihx@licp.cas.cn (H.L.)
}

Citation: Wang, W.; Ling, X.; Wang, R.; Nie, W.; Ji, L.; Li, H. Structure and Characterization of TiC/GLC Multilayered Films with Various Bilayers Periods. Coatings 2021, 11, 787. https://doi.org/10.3390/ coatings 11070787

Academic Editor: Jean-François Berret

Received: 15 June 2021

Accepted: 28 June 2021

Published: 30 June 2021

Publisher's Note: MDPI stays neutral with regard to jurisdictional claims in published maps and institutional affiliations.

Copyright: (c) 2021 by the authors. Licensee MDPI, Basel, Switzerland. This article is an open access article distributed under the terms and conditions of the Creative Commons Attribution (CC BY) license (https:// creativecommons.org/licenses/by/ $4.0 /)$.

\begin{abstract}
The spontaneously self-organizing multilayered graphite-like carbon (denoted as GLC) / TiC films with various bilayer periods in the range of 13.3-17.5 $\mathrm{nm}$ were deposited on silicon and 1Cr18Mn8Ni5N stainless steel substrates using closed field magnetron sputtering deposition facility. The microstructures and chemical compositions of the prepared multilayered films were characterized by scanning electron microscopy, high resolution transmission electron microscopy, X-ray diffraction and X-ray photoelectron spectroscopy respectively. The self-organizing multilayered structures in all of the films consisted of titanium carbide layers and $s p^{2}$-rich carbon layers periodically alternate arrangement. The TiC contents and bilayer periods of the multilayered films can be controlled by means of adjusting of sputtering current of graphite target. Furthermore, the mechanical and tribological performances of the prepared films were appraised by nano-indentor, scratch measures, and ball-on-plate tribometer respectively. The results indicated that multilayer structure endowed the as-deposited TiC/GLC films outstanding mechanical and tribological properties, especially the multilayer film with $15.9 \mathrm{~nm}$ bilayer period deposited at $10 \mathrm{~A}$ sputtering current showed the excellent adhesion strength and hardness; Simultaneously it also exhibited the lowest average friction coefficient in the humid environment owing to its high content of $s p^{2}$ hybrid carbon.
\end{abstract}

Keywords: graphite-like carbon; multilayer films; self-organization; mechanical and tribological properties

\section{Introduction}

Amorphous carbon films that mainly compose of $s p^{2}$ and $s p^{3}$ hybrid carbon shows a great prospect in the field of aerospace as the solid lubrication films due to its excellent mechanical and tribological properties [1-3]. Especially, the graphite-like carbon films (GLC films) with a high content of $s p^{2}$ carbon exhibited lower friction coefficient, higher wear resistance and hardness compared with other types of amorphous carbon films [4-6]. Nevertheless, high internal stresses cause growth and poor adaptability to different environments of tribological properties, especially in the damp environments, preventing the deposition of thick films and leading to massive failure, which critically restrains its industrialization $[7,8]$. It was found that taking advantage of depositing an interlayer or incorporating metal could effectively minimize the internal stress and ameliorate the environmental adaptability of GLC films $[9,10]$. The fabrication of multi-layer structure is another significant approach by uniformly introducing various components layers into GLC films [11]. According to forming the interfaces and grain boundaries in the multilayers of the films, the crack propagations and the stress concentrations can be deflect and reduce plentiful, consequently enhancing the mechanical and tribological properties [12,13]. A 
large number of works have been attempt by forming metal/carbon (e.g., W, Cr, and Ti etc.) multilayered films [10-12] and these multilayered films shown improved adhesive strength and favorable tribological stability, the complicated fabrication procedures that required regulating the deposition parameters periodically seriously impeded their applications however. Moreover, the multilayered structures were composed of metallic carbide/carbon displayed the better toughness, hardness and tribological performance compared to consisting of the pure metal layer and carbon layers [14,15].

The bilayer period played a significant role in the properties of the multilayered film by controlling their amount to an optimal values reported by Stueber et al. [16]. For instance, Chen R. et al. [17] reported that the TaN/a-CNx multilayer film with a thin bilayer period of $10 \mathrm{~nm}$ exhibited the best mechanical and tribological properties. Liu D.G. et al. [18] revealed that the carbon nitride multilayer film with a thick bilayer period of $60 \mathrm{~nm}$ had the highest hardness and best tribologial performances, which presented promising prospects for industrial applications. Recently, the self-organizing metal/carbon nano-multilayered films have attracted enormous attentions because of their extraordinary performances and facile preparation process $[19,20]$. Few works focused on discussing the influence of bilayer periods on the mechanical and tribological properties of spontaneously multilayered films although it had been proved that bilayer period dominate the multilayered films properties [21]. Consequently, it is definitely worth to tailoring the properties of selforganizing multilayered films by regulating the bilayer periods, which possessed a great significance to the development of self-organized multilayered carbon-based films with outstanding performances.

In this present work, the multilayered films composed of TiC layers and GLC layers periodically alternate arrangement was self-organized by a facile closed field magnetron sputtering deposition facility. And a series of TiC/GLC multilayer films with different bilayer periods were fabricated by changing the sputtering current of graphite target. The influences of bilayer periods on the mechanical and tribological properties of selforganizing multilayered TiC/GLC films were systematically investigated. Meanwhile, the promotive mechanisms of microstructures in mechanical and tribological performances of multilayered films were also put forward.

\section{Experimental Section}

\subsection{Samples Preparation}

The closed field medium frequency magnetron sputtering facility equipped with four magnetron targets was employed to prepare the TiC/GLC multilayered films. The samples were grown on the surfaces of single crystal wafers of silicon (100) and $1 \mathrm{Cr} 18 \mathrm{Mn} 8 \mathrm{Ni} 5 \mathrm{~N}$ stainless steel. The high purity argon $(99.99 \%)$ was used as a sputtering gas of titanium and graphite targets (rectangle with $94 \times 300 \mathrm{~mm}^{2}, 99.9 \%$ purity). The $\mathrm{Si}(100)$ substrates were used for analysis of microstructure and composition and the stainless steel substrates for testing of mechanical and tribological properties. The four sputtering targets were symmetrical placed in the chamber to form a closed magnetic field for the sake of improving deposition efficiency of samples. Among them, two targets were connected to a medium frequency alternating current power supply and for deposition of titanium. The other two were graphite targets connected to the other alternating current power supply similarly. The detailed schematic diagram of the deposited apparatus has been described elsewhere [15]. The thin Ti interlayer was deposited onto the substrates prior to multilayers growth, with a $200 \mathrm{~V}$ negative bias and $6 \mathrm{~A}$ sputtering current for $10 \mathrm{~min}$. Then Ti/C gradient content transition layer was deposited by gradually raising the graphite target sputtering current from 2 to $12 \mathrm{~A}$ for $10 \mathrm{~min}$. The Ti interlayer and Ti transition layers were deposited on the substrates in order to enhance the adhesive strength. Afterwards, the self-organizing multilayered films consisted of ordered carbon layer and C-Ti composite layer were grown by adjusting the sputtering currents of graphite were 6, 8, 10 and $12 \mathrm{~A}$ respectively. Meanwhile the titanium sputtering current was fixed at $6 \mathrm{~A}$. The substrates fasten to the sample holder and the distance from sputtering target to holder is $50 \mathrm{~mm}$. During 
the deposition process, the sample holder planetary rotated in the clockwise direction with $5 \%$ s. Prior to deposition, the substrates were ultrasonic cleaning in acetone for $25 \mathrm{~min}$ to remove the impurities and quickly dried in the air. Then Ar+ plasma bombardment was used to remove the native surface oxide in deposition chamber. The vacuum degree in the chamber was firstly pumped down to $7.0 \times 10^{-3} \mathrm{~Pa}$, and then regulating to a stationary pressure of 1.0 Pa according to filling with Ar gas. During the deposition process, no bias voltage was applied on the substrates, the substrate temperature was $80^{\circ} \mathrm{C}$ approximately and the deposition time was $2 \mathrm{~h}$ under all deposition process.

\subsection{Sample Characterization}

The thickness and cross-section structure morphology of as-prepared films were analyzed via a SU8020 field emission scanning electron microscopy (FESEM, HITACHI, Tokyo, Japan). The cross-sections of various as-deposited TiC/GLC films were bombarded with focused ion beam (ion source: gallium liquid metal) to afford thin foils for FESEM analysis as well as microstructure characterization by high-resolution transmission electron microscopy (HRTEM; FEI TecnaiG2TF20FE-TEM, Hillsboro, OR, USA, accelerating voltage: $200 \mathrm{kV}$ ). The element distribution of the TiC/GLC films were revealed on multifunctional X-ray photoelectron spectroscopy (XPS, Perkin-Elmer PHI-5702, Wellesley, MA, USA) and $\mathrm{Al}-\mathrm{K} \alpha$ was used as the exciting source with binding energy of $\mathrm{Au}(4 \mathrm{f})$ as the reference. The carbon atomic bond features of the TiC/GLC films were characterized by Raman spectroscopy (Raman, Horiba LabRam HR800, Tokyo, Japan) under the excitation of laser at 532 $\mathrm{nm}$. Moreover, a Rigaku D/max-2500 facility operating with $\mathrm{Cu}-\mathrm{K}$ radiation was conducted to record the X-ray diffraction (XRD, Tokyo, Japan) patterns of the TiC/GLC films.

\subsection{Mechanical and Tribological Properties of the Multilayered Films}

The nano-hardness of the prepared TiC/GLC composite films was measured with a nano indenter (a Berkovich $120 \mu \mathrm{m}$ diamond probe tip, Nano Hardness Tester, Anton Paar, Neuchatel, Switzerland). The indentation depth was limited to less than $10 \%$ of films thickness (about $100 \mathrm{~nm}$ ) so as to minimize the influence of the substrate. In order to reduce errors, each testing was repeated at least three times. Their adhesion to substrate was measured with the nano scratch (Nano Scratch Tester, Anton Paar). The tribological properties of the multilayer films were measured on the tribometer (CSM ball-on-disk, Neuchatel, Switzerland) at ambient air environment with steel ball friction pair (diameter: $6 \mathrm{~mm}, \mathrm{GCr} 15)$. The tests were carried out at a normal load of $5 \mathrm{~N}$ at a sliding velocity of $8 \mathrm{~cm} / \mathrm{s}$ in ambient air (60\% RH). The test duration was up to $30 \mathrm{~min}$ with $5 \mathrm{~mm}$ reciprocal distance. The morphologies of worn trace of the films were observed by Olympus optical microscope (STM6, Tokyo, Japan).

\section{Results and Discussion}

The XPS C1s and Ti2p peaks of the as-prepared films prepared on silicon (100) with different sputtering currents of graphite target as well as their Ti content as the function of sputtering current of graphite as shown in Figure 1. It is obviously that the C1s peaks are composed of two peaks centered at $281.4 \mathrm{eV}$ and $284.6 \mathrm{eV}$ respectively. The intensity of Ti $2 \mathrm{p}$ peak decreases with sputtering current of graphite target, which indicates that the Ti content in the prepared films trend to decrease therewith (Figure 1b). And the average titanium concentration of the TiC/GLC films trends to continuously decrease from 13.4 at. $\%$ to 3.6 at. $\%$ as the sputtering current of graphite increased from 6 to 12 A shown in Figure 1c. The peaks of the Ti 2p3/2 and Ti 2p1/2 at $454.1 \pm 0.2$ and $460.4 \pm 0.2 \mathrm{eV}$ in the Ti $2 \mathrm{p}$ spectra corresponds to Ti-C bond (in the form of titanium carbides) in the bulk of the films [22]. Although the intensity of Ti $2 \mathrm{p} 1 / 2$ and Ti $2 \mathrm{p} 3 / 2$ spectra are found to decrease with sputtering current of graphite target, the outlines acquired at high sputtering currents seems more symmetric compared with low sputtering currents. It is indicated that stoichiometric titanium carbides are preferred forming in the films with high carbon content. Contrarily, the films deposited at low sputtering currents (especially deposited 
at 6 A) consists of numerous non-stoichiometry titanium carbides due to the deficiency in carbon atoms, resulting in the formation of asymmetric Ti $2 p$ spectra [6]. Besides, the strong titanium dioxide peaks presented in the XPS analysis were caused by the adsorbed oxygen in the air during characterization process due to the titanium atom easily binds to the oxygen atom [9].
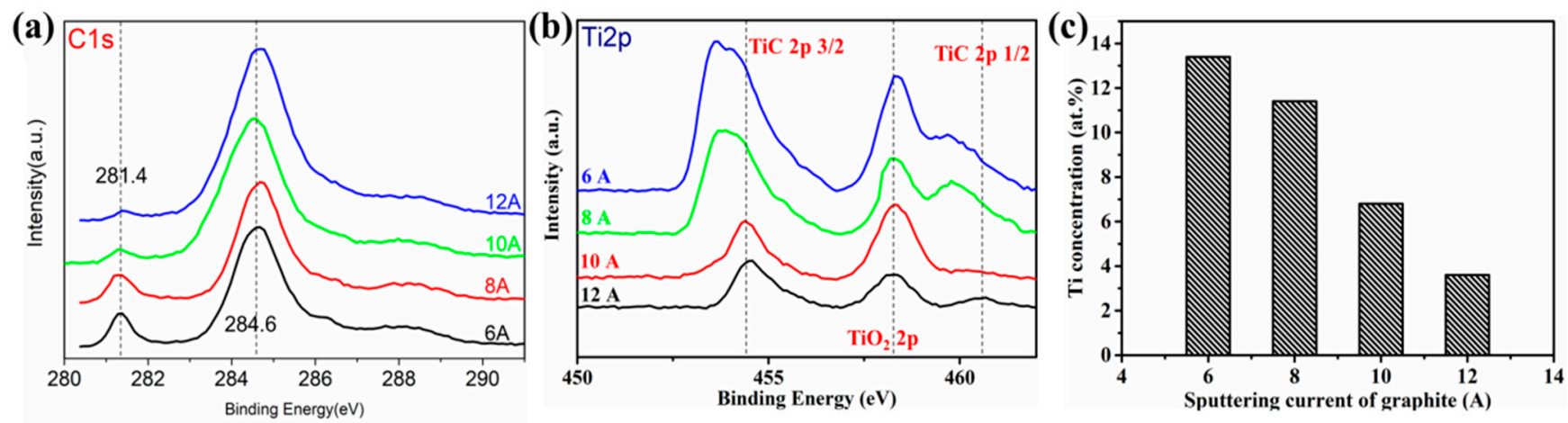

Figure 1. XPS characterizations (a) C1s peaks, (b) Ti 2p peaks and (c) Ti content of the films deposited at various sputtering currents of graphite.

As shown in Figure 2, the C1s XPS spectra were deconvoluted to analyze overlapping peaks. Gaussian function was used to decompose the C1s XPS spectra of TiC/GLC multilayered films into four main peaks of Ti-C bond, $s p^{2}-\mathrm{C}, \mathrm{C}-\mathrm{O}$ bond, and $\mathrm{O}=\mathrm{C}-\mathrm{O}$ bond and the corresponding binding energy were $281.4 \mathrm{eV}, 284.6 \mathrm{eV}, 286.1 \mathrm{eV}$, and $288.1 \mathrm{eV}$ respectively [15]. Therefore, according to XPS analysis, it can be deduced that the studied films are dominated by $s p^{2}$ hybrid carbon and containing a few titanium carbides. Therefore, the as-prepared films were classified to the TiC/GLC composite films. Table 1 shows the area ratios of $\mathrm{C}=\mathrm{C}$ and $\mathrm{C}-\mathrm{Ti}$ bonds to total area of XPS C1s peaks at different sputtering currents. The area ratios were calculated from XPS fitting curves shown in Figure 2, this ratio is proportional to the graphitic in carbon film [23]. The ratios of $C=C$ bond $A_{C=C} / A$ (area ratios) trend to increase with sputtering and the area ratios of $\mathrm{C}-\mathrm{Ti}$ bond $\left(\mathrm{A}_{T i-\mathrm{C}} / \mathrm{A}\right)$ decrease with sputtering currents, where $\mathrm{A}$ is the total area of $\mathrm{C} 1 \mathrm{~s}$ profile. It proves that the sputtering current of graphite played an important factor in affecting the contents of graphitic structures and titanium carbides in the prepared films.

Figure 3 showed the cross-sectional FESEM morphologies of TiC/GLC multilayer films prepared at various sputtering currents of graphite. The Ti interlayer and Ti transition layers with $160 \mathrm{~nm}$ thickness were deposited on silicon and $1 \mathrm{Cr} 18 \mathrm{Mn} 8 \mathrm{Ni} 5 \mathrm{~N}$ stainless steel substrates. The multilayered structure was clearly seen in all of the films' high resolution cross-sectional morphologies with red wire-frame. The thicknesses of the TiC/GLC multilayered films were 1.15, 1.27, 1.34, and $1.54 \mu \mathrm{m}$ at the sputtering currents of $6,8,10$, and 12 A corresponding to the deposition rates of $9.58,10.58,11.17$ and $12.83 \mathrm{~nm} / \mathrm{min}$ respectively. It can be seen that the thickness of the as-prepared films was found to increase with sputtering current of graphite. As shown in Figure 3, all the prepared multilayered films are composed of a layered feature by alternating stacking lighter carbon layers and darker TiC layers. It was found that the bilayer period of multilayer films are varied with sputtering currents, and the multilayered microstructure deposited at different sputtering current displayed some differences in interfaces of carbon layers and $\mathrm{TiC}$ layers. The interfaces of carbon layers and TiC layers deposited at 6 and $8 \mathrm{~A}$ seemed more distinct and rectilinear compared to the films prepared at 10 and $12 \mathrm{~A}$. The bending of the interfaces was mainly attributed to the increase of thickness of bilayer period. The difference in thickness between carbon layers and $\mathrm{TiC}$ layers enlarged with increasing sputtering current of graphite, which would be adverse to keep the interfaces rectilinear in the multilayered films $[19,24]$. Furthermore, the interfaces of the TiC/GLC multilayered films deposited 
at high sputtering currents became more curved compared to the films prepared at low sputtering currents.
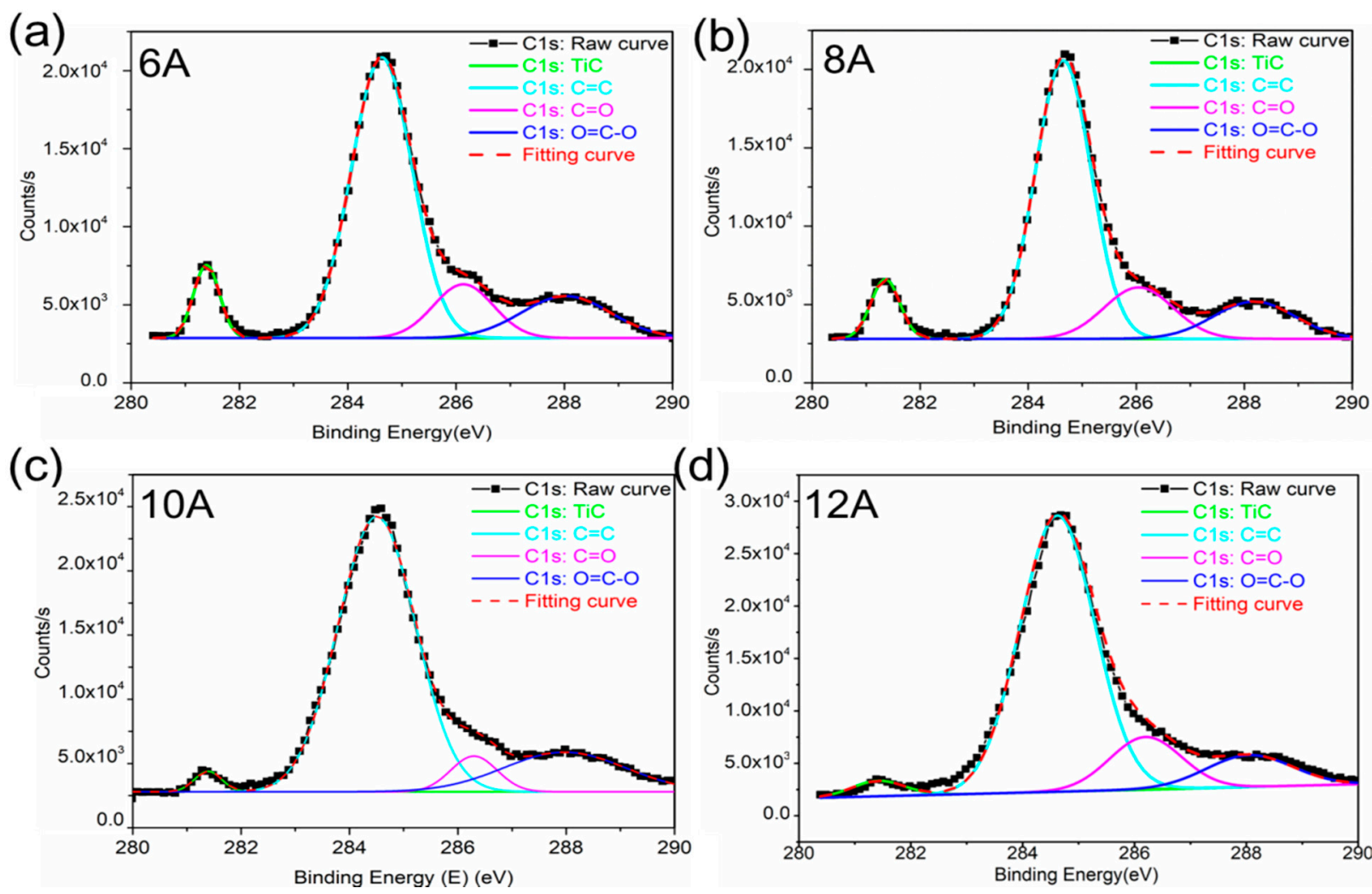

Figure 2. Gaussian fitting of $\mathrm{C} 1 \mathrm{~s}$ of the films prepared at various sputtering currents of graphite.

Table 1. The Ratios of $\mathrm{C}=\mathrm{C}$ and $\mathrm{C}-\mathrm{Ti}$ Bonds as Function of Sputtering Current of Graphite for Prepared Multilayered Films.

\begin{tabular}{cccccc}
\hline \multicolumn{2}{c}{ Sputtering Current of Graphite } & $\mathbf{6 ~ A}$ & $\mathbf{8 ~ A}$ & $\mathbf{1 0} \mathbf{A}$ & $\mathbf{1 2} \mathbf{A}$ \\
\hline \multirow{2}{*}{ Area ratio } & $\mathrm{A}_{C=C} / \mathrm{A}$ & 0.611 & 0.659 & 0.752 & 0.772 \\
& $\mathrm{~A}_{T i-C} / \mathrm{A}$ & 0.078 & 0.061 & 0.038 & 0.023 \\
\hline
\end{tabular}

The detailed layer features and crystalline phase of multilayered TiC/GLC films were analyzed from HRTEM and their corresponding selected area electron diffraction (SAED) pattern as shown in Figure 4. It is obviously that the multilayered structure composed of sequentially altering TiC and C layers is formed in all the films. As shown in Figure $4 \mathrm{e}-\mathrm{h}$, the bilayer period (the total thickness of $C$ layer and TiC layer) of films were about $13.3 \mathrm{~nm}$, $14.8 \mathrm{~nm}, 15.9 \mathrm{~nm}$ and $17.5 \mathrm{~nm}$ respectively with increasing sputtering current from 6 to $12 \mathrm{~A}$. The thickness of the $\mathrm{TiC}$ is constant $(10.2 \mathrm{~nm})$ due to the sputtering current of titanium is unchanged. The thickness of carbon layers were $3.1 \mathrm{~nm}, 4.6 \mathrm{~nm}, 5.7 \mathrm{~nm}$ and $7.3 \mathrm{~nm}$ respectively by adjusting sputtering current of graphite target. The SAED patterns inserted in Figure $4 a-d$ displays four diffraction rings, indicating a polycrystalline $\mathrm{TiC}$ phase with orientations of $(1,1,1),(2,0,0),(2,2,0)$ and $(3,1,1)[23]$. There are also some nanocrystallines at the interface between the Ti-C layers and $\mathrm{Clayers}$ with the combination of the HRTEM image, owing to atomic diffusion of Ti and C. Conventionally, the fabrication of nano-multilayered structure films need to regulating a certain experimental parameters periodically (such as turn on/off sputtering power supply, working gas etc.) during the deposition process [21,25]. In this work, we prepared the spontaneously self-organizeing multilayers structure in the TiC/GLC film by making the substrates periodically exposed to the titanium and graphite targets with $5 \%$ s rotational speed. Furthermore, it indicated 
that the multilayered structure was spontaneously formed in the TiC/GLC films, which simplified the preparation process of multilayer films greatly.

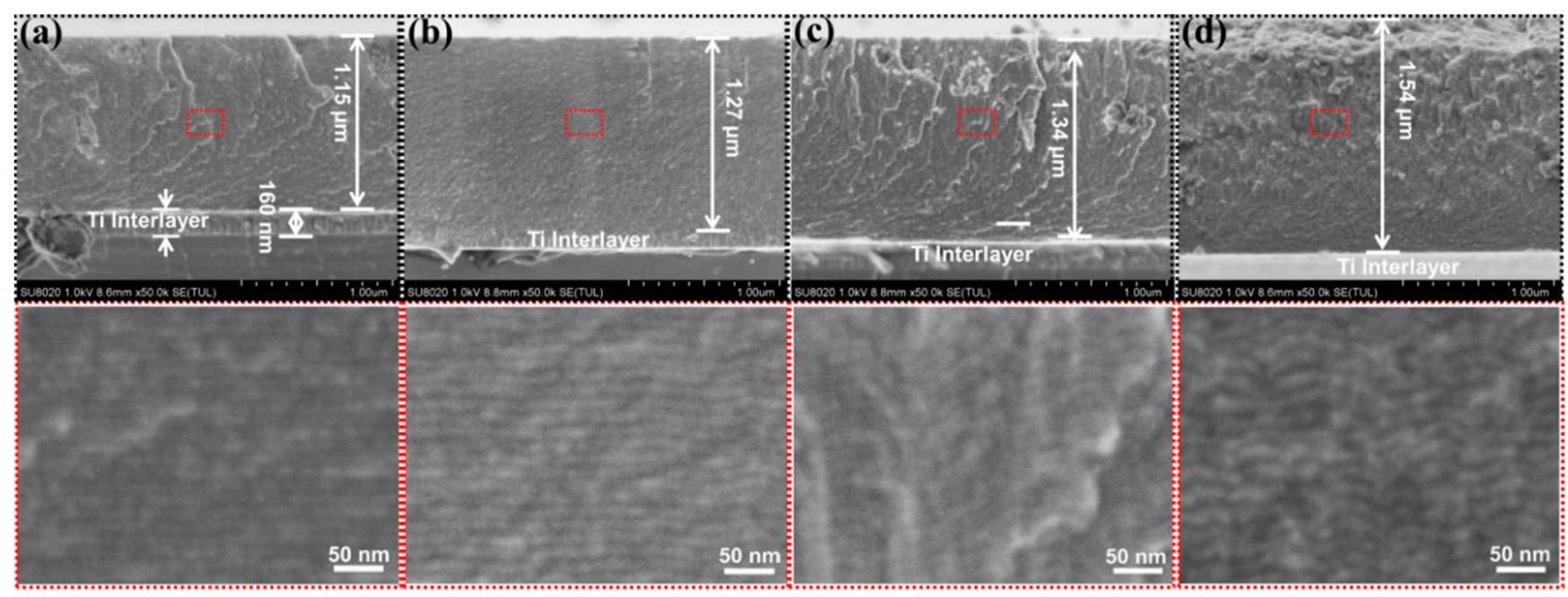

Figure 3. Cross-sectional FESEM morphologies of the multilayered films with different target currents of graphite: (a), 6 A; (b), $8 \mathrm{~A} ;(\mathbf{c}), 10 \mathrm{~A} ;(\mathbf{d}), 12 \mathrm{~A}$ and their corresponding high resolution cross-sectional morphologies with red wire-frame.
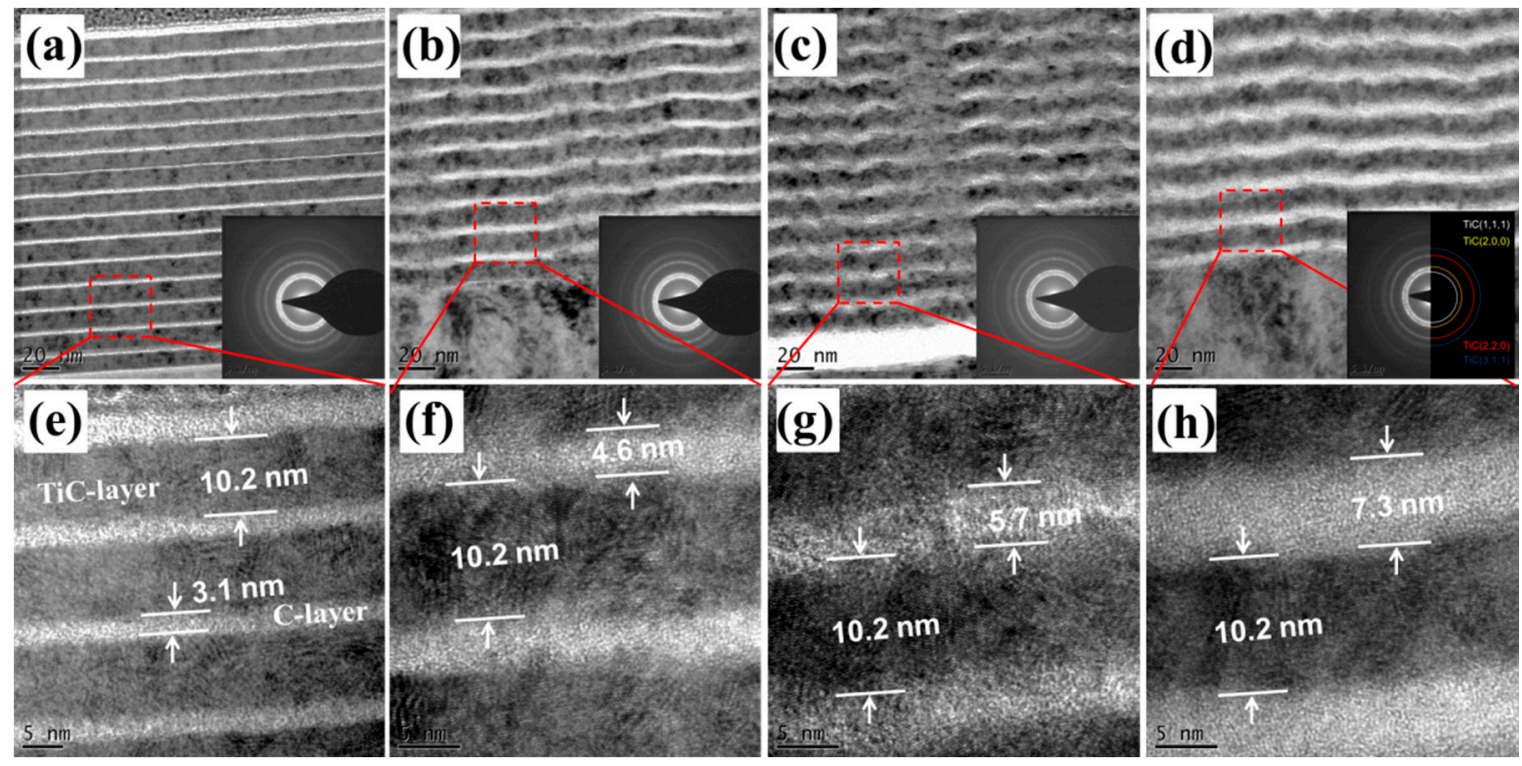

Figure 4. Cross-section TEM morphologies with inserted corresponding SAED pattern and HRTEM images of the films with different sputtering currents of graphite: (a,e) 6 A; (b,f) 8 A; (c,g) 10 A and (d,h), 12 A respectively.

The Raman spectra of TiC/GLC multilayer films deposited at various sputtering current are shown in Figure 5a. It is revealed that all Raman spectra presented a broad and skew peak ranging from $1000-2000 \mathrm{~cm}^{-1}$. And was composed of the overlapped $D$ peak (centered at $1350 \mathrm{~cm}^{-1}$ ) and the $\mathrm{G}$ peak (centered at $1580 \mathrm{~cm}^{-1}$ ) corresponding to the $\mathrm{A}_{1 \mathrm{~g}}$ and $E_{2 g}$ vibrational modes of graphite respectively [26]. The peaks at 265 and $600 \mathrm{~cm}^{-1}$ are associated with the TiC crystal [27]. And the intensity of these peaks increases with sputtering current of graphite, which indicating the quality of the TiC crystal has been improved. Because of the different resonances degree of the $G$ and $D$ bands, the increased intensity of D and G bands usually reflects the increased content of $s p^{2}$ hybrid carbon. As the sputtering current increased from 6 to $10 \mathrm{~A}$, the intensity of the D and G bands of the films increased, but when the sputtering current was beyond $10 \mathrm{~A}$, it decreased drastically. It proved that the addition of carbon layer thickness would influence the 
formation of $s p^{2}$ bonds in the TiC/GLC films. In order to clear the effect of sputtering current on the bonding structures of as-deposited films furtherly, the Raman spectra were fitted with Gaussians line shape to evaluate the ratio of $D$ to $G$ peak intensity $\left(\mathrm{I}_{\mathrm{D}} / \mathrm{I}_{\mathrm{G}}\right)$, and the $\mathrm{I}_{\mathrm{D}} / \mathrm{I}_{\mathrm{G}}$ ratio data were listed in Table 2 . The $\mathrm{I}_{\mathrm{D}} / \mathrm{I}_{\mathrm{G}}$ value can be used to determine the ratio of $s p^{3}$ to $s p^{2}$ carbon bonding, where an increase in $\mathrm{I}_{\mathrm{D}} / \mathrm{I}_{\mathrm{G}}$ indicates a higher $s p^{2} / s p^{3}$ ratio in the film $[25,28]$. As seen in Table 2 , the estimated $\mathrm{I}_{\mathrm{D}} / \mathrm{I}_{\mathrm{G}}$ ratio increased first and then decreased with sputtering current. Especially, the highest $\mathrm{I}_{\mathrm{D}} / \mathrm{I}_{\mathrm{G}}$ ratio of 4.69 was obtained when the sputtering current was $10 \mathrm{~A}$. The result indicates that the size of the $s p^{2}$ clusters enlarged and the $s p^{2}$ fraction increased. The XRD analysis was used to study components of the films shown in Figure 5b. Four strong peaks at $2 \theta$ of 35.9, 41.7, 60.4 and 72.4 deg correspond to the reflection from $(1,1,1),(2,0,0),(2,2,0)$ and $(3,1,1)$ planes of $\mathrm{TiC}$ crystallite [29]. In addition, it can be observed that the intensity of the TiC peaks decreases with the sputtering currents as well as the four peaks shapes become more protruding with increasing sputtering current, which indicated the improvement of crystallinity of the TiC crystal. With increase of sputtering currents, the number of deposited carbon atoms increased which satisfied the stoichiometric ratio of Ti-C bond and improves the degree of TiC crystallite.
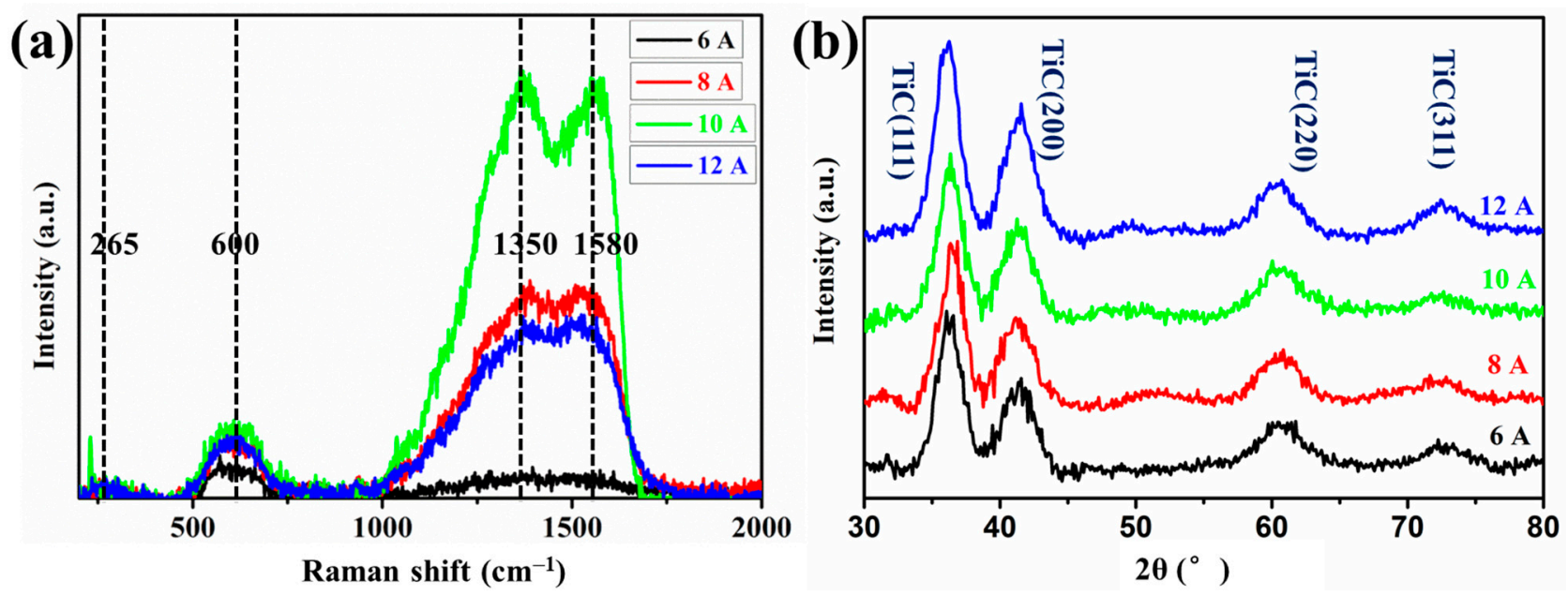

Figure 5. (a) Raman spectra and (b) XRD pattern of TiC/GLC multilayered films at various sputtering currents of graphite.

Table 2. $\mathrm{I}_{\mathrm{D}} / \mathrm{I}_{\mathrm{G}}$ ratio as function of sputtering currents of graphite for TiC/GLC films.

\begin{tabular}{ccccc}
\hline Sputtering Current of Graphite & $\mathbf{6 ~ A}$ & $\mathbf{8 ~ A}$ & $\mathbf{1 0 ~ A}$ & $\mathbf{1 2} \mathbf{A}$ \\
\hline $\mathrm{I}_{\mathrm{D}} / \mathrm{I}_{\mathrm{G}}$ & 1.16 & 4.61 & 4.69 & 4.57 \\
\hline
\end{tabular}

The tribological performances of the TiC/GLC multilayer films in ambient air with high humidity $(60 \% \mathrm{RH})$ were evaluated by a ball-on-disk test system. The stainless steel substrates with as-prepared multilayer films were used for friction and wear measurements. In high humidity environment, a small amount of suspended bonds on the surface of films will be further saturated by water molecules, which is conducive to improving the friction properties of graphite-like carbon films [30]. Figure 6a shows the friction coefficient as a function of sliding distance of multilayered TiC/GLC films with various bilayer periods. Average friction coefficients of the films were calculated from the collected data and the friction coefficients were at the stable stage (after roughly $10 \mathrm{~m}$ ) shown in Figure $6 \mathrm{~b}$. The average friction coefficient of the TiC/GLC multilayered films were $0.141,0.122,0.101$, and 0.130 corresponding to the sputtering currents were $6,8,10$, and 12 A respectively. All the films depicted relatively low coefficient of friction (below 0.15 ) against steel ball, and the films with $15.9 \mathrm{~nm}$ bilayer period deposited at $10 \mathrm{~A}$ sputtering current exhibiting the lowest value of 0.101 against steel ball. When the sputtering current is over $10 \mathrm{~A}$, the 
friction coefficient decreased after $50 \mathrm{~m}$ distance but the friction coefficient is undulating. Low friction coefficient may be attributed to the $s p^{2}$ hybrid carbon in the multilayered architecture. Our results indicated that the friction coefficient of the multilayered films first decreases with the increase of bilayer period from $13.3 \mathrm{~nm}$ to $15.9 \mathrm{~nm}$ and then slight degeneration as the bilayer period further increases to $17.5 \mathrm{~nm}$, which is identical with mutative trend of $s p^{2}$ hybrid carbon content in the multilayer films from the Raman spectra seen in Figure 5a. It is known that in the tribological testing of carbon-based film, the graphitized $s p^{2}$ hybrid carbon in the film is propitious to enhance the shear effect and reduce the friction coefficient [31].
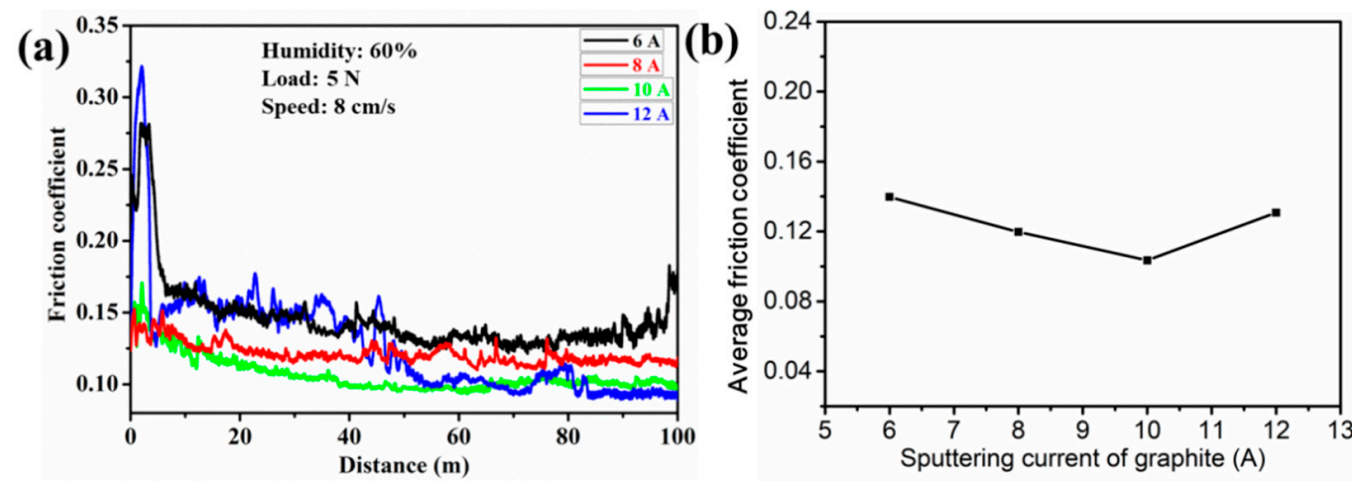

Figure 6. (a) Friction coefficients of TiC/GLC multilayer films as a function of sliding distance, (b) average friction coefficients of TiC/GLC multilayer films deposited at various sputtering currents.

Figure 7 shows optical images of the worn tracks on the multilayered films and worn morphologies of rubbing pairs in ambient air with high humidity. The width of worn tracks of the films show the decreasing trend as the bilayer period increases from $13.3 \mathrm{~nm}$ to $17.5 \mathrm{~nm}$, and has the lowest value of $477 \mu \mathrm{m}$ for the film with bilayer period of $17.5 \mathrm{~nm}$ deposited at sputtering current of $12 \mathrm{~A}$. And a number of black wear debris was found alongside the wear tracks due to the fluctuation of friction coefficient. Nevertheless, the wear track of the film deposited at $10 \mathrm{~A}$ is sleek and little wear debris were observed alongside the wear track. Similarly, cracks initiate and propagate leading to the spall of the film from the substrate. The varied trend of the worn size of the rubbing pairs is consistent with that of the wear tracks width.

The nano hardness $(\mathrm{H})$ and elastic modulus (E) of as-deposited TiC/GLC multilayered films as a function of various sputtering currents showed in Figure 8a. The results indicated that bilayer period played an important effect on the $\mathrm{H}$ and $\mathrm{E}$, where various trends of $\mathrm{H}$ and $\mathrm{E}$ were opposite with the increase of sputtering current of graphite. As the bilayer period increased from $13.3 \mathrm{~nm}$ to $15.9 \mathrm{~nm}$, the hardness of the films increased from 11.48 to 12.75 GPa but abruptly decreased down to $12.41 \mathrm{GPa}$ at $17.5 \mathrm{~nm}$. Combining this tendency with the XRD and XPS analysis results seen in Figure 6, it indicated that the excellent hardness was dominated by two factors for the multilayered films. On the one hand, all the TiC/GLC films exhibited high hardness owing to strengthen effect of hard TiC crystallite [32]. On the other hand, the $\mathrm{TiC}$ crystalline nanoparticles in the multilayer films can inhibit the dislocations motion and produce the strengthening effect. Meanwhile, the interface is a very important factor for hardness improvement [25]. The film with $15.9 \mathrm{~nm}$ bilayer period deposited at $10 \mathrm{~A}$ displayed the maximum hardness because of its large hard TiC crystallite constitutes, meanwhile, the ordered microstructure was compared with others. The H/E ratios of the films are also presented in Figure 8b. The H/E ratio is associated with resistance to plastic deformation, and a high $\mathrm{H} / \mathrm{E}$ ratio is advantageous to wear resistance [33]. The H/E ratio of the TiC/GLC multilayered film with $15.9 \mathrm{~nm}$ bilayer period showed the maximum value and outstanding wear resistance. 


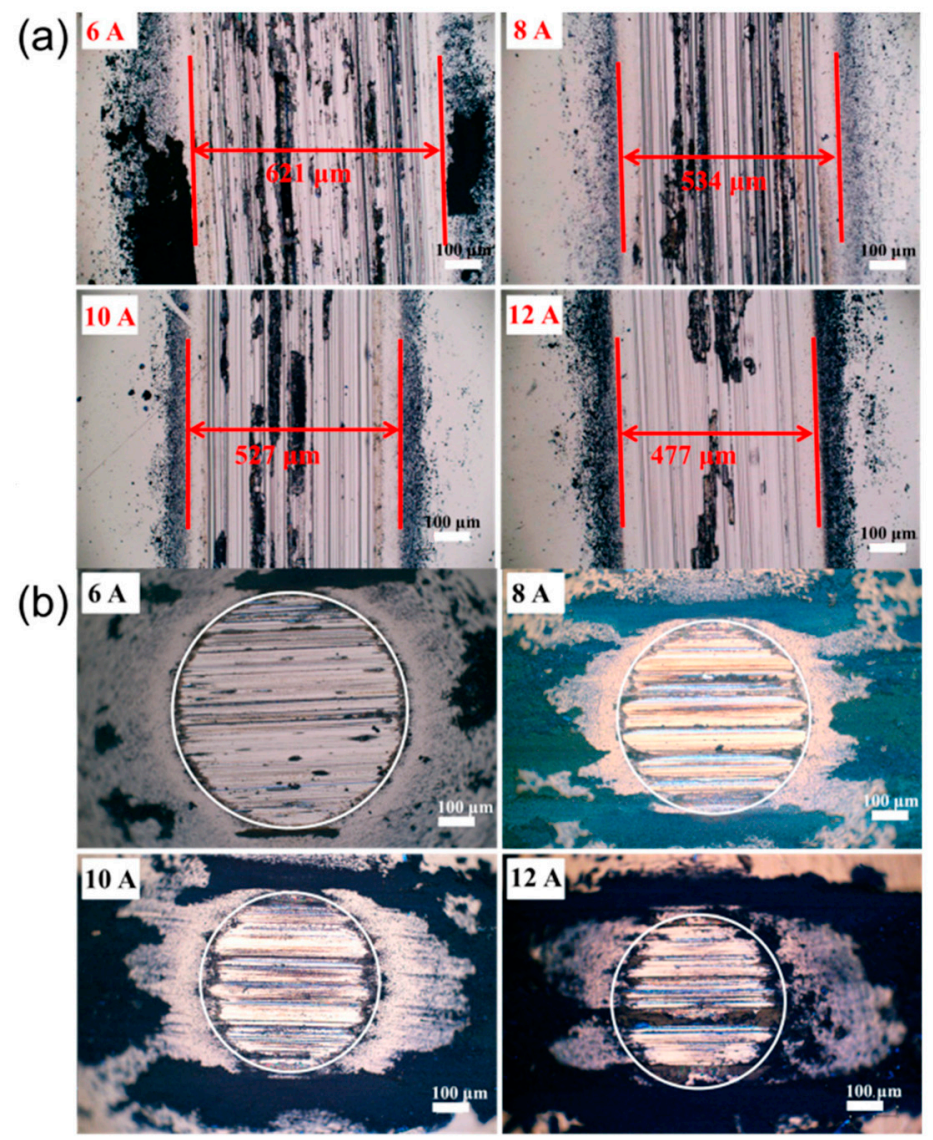

Figure 7. Optical images of (a) worn tracks and (b) worn morphologies of rubbing pair of the multilayer films deposited with various sputtering currents.
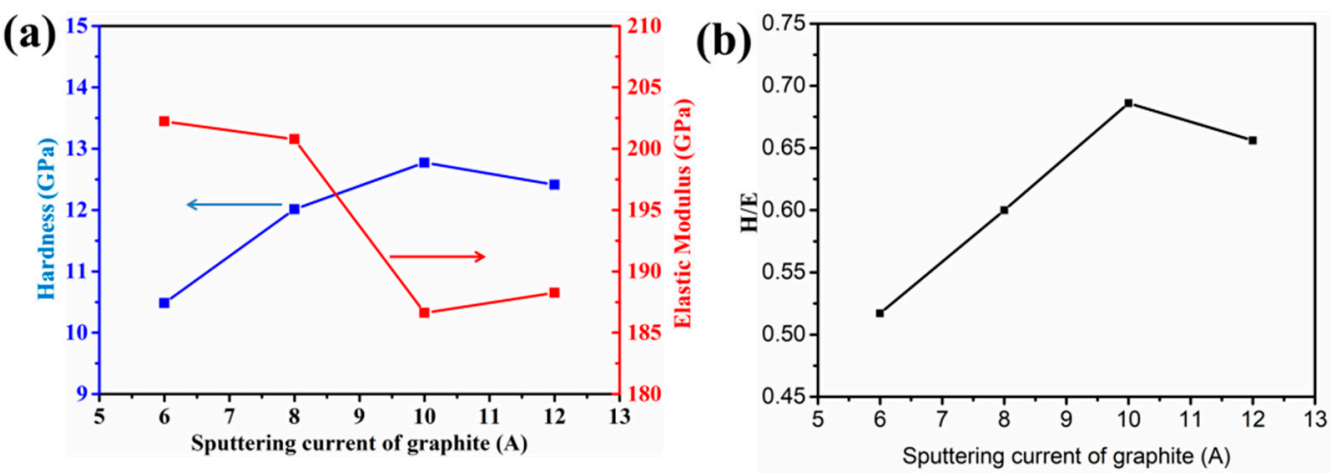

Figure 8. (a) Hardness and elastic modulus; (b) H/E ratio of the multilayered films with various bilayer periods.

Scratch testing is a common way to evaluate the adhesion strength of the film to substrate. Figure 9 shows the optical images of the scratch tracks versus applied load of the multilayer films with various bilayer periods. For comparison, pure GLC film was prepared under the condition of $10 \mathrm{~A}$ sputtering current of graphite and the other deposition parameters were kept to be identical. According to the optical pictures of scratch tracks of multilayered films, many flaking appeared in and beside the scratch track of the films and lots of cracks in the scratch. The cohesion failure may be caused by crack generation and propagation under applied load. As clearly seen in Figure 9, the critical load of TiC/GLC films was significantly improved compared with pure GLC film due to forming the multilayer structure in the film, especially for the films with 14.8 and 
$15.9 \mathrm{~nm}$ bilayer period (critical load $\sim 16 \mathrm{~N}$ ), which exhibiting promising potential in the development of industrial applications.

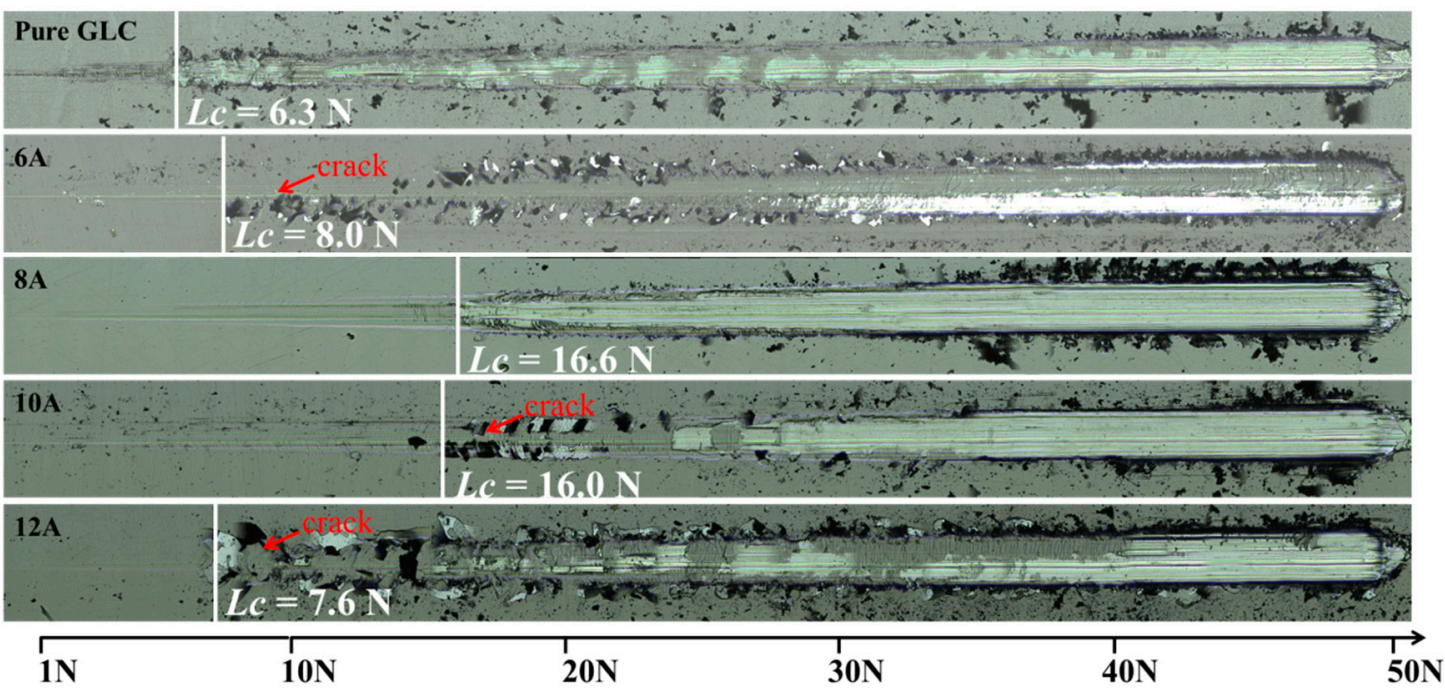

Figure 9. Scratch tracks of the TiC/GLC multilayered films and pure GLC film.

\section{Conclusions}

Here, a series of self-organizing multilayer films composed of TiC layers and C layers with periodically alternate arrangement were prepared via closed field magnetron sputtering deposition. The TiC/GLC multilayered films with various bilayer periods of $13.3-17.5 \mathrm{~nm}$ were gown by adjusting the sputtering current of graphite target. The results indicated that the microstructures, mechanical and tribological properties of TiC/GLC multilayer films exhibit a significant dependence on the bilayer period. With the increase in the bilayer period by enlarging the thickness of carbon layer, the degree of TiC crystallite and $s p^{2}$ hybrid carbon content in the films was improved. Especially for the multilayer film with a bilayer period of $15.9 \mathrm{~nm}$ deposited at 10 A sputtering current, that showed the excellent adhesion strength, hardness and lowest average friction coefficient in the humid environment.

Author Contributions: Conceptualization, investigation, draft preparation and writing-original, W.W.; data curation, R.W. and W.N.; writing-review and editing, X.L.; validation, H.L.; funding acquisition, L.J. and H.L. All authors have read and agreed to the published version of the manuscript.

Funding: This research was funded by National Natural Science Foundation of China, Grant Nos. 51775537 and U1637204, the Youth Foundation of Lanzhou Jiaotong University, Grant No. 2020008.

Institutional Review Board Statement: Not applicable.

Informed Consent Statement: Not applicable.

Data Availability Statement: Data is contained within the article.

Conflicts of Interest: The authors declare no conflict of interest.

\section{References}

1. Robertson, J. Diamond-like amorphous carbon. Mater. Sci. Eng. R Rep. 2002, 37, 129-281. [CrossRef]

2. Erdemir, A.; Donnet, C. Tribology of diamond-like carbon films: Recent progress and future prospects. J. Phys. D Appl. Phys. 2006, 39, R311-R327. [CrossRef]

3. Liu, X.; Hao, J.; Lv, Y.; Cui, X. The Effects of Precursor $\mathrm{C}_{2} \mathrm{H}_{2}$ Fraction on Microstructure and Properties of Amorphous Carbon Composite Films Containing Si and Ag Prepared by Magnetron Sputtering Deposition. Nanomaterials 2019, 9, 528. [CrossRef] [PubMed]

4. Wang, Y.; Wang, L.; Zhang, G.; Wang, S.C.; Wood, R.J.K.; Xue, Q. Effect of bias voltage on microstructure and properties of Ti-doped graphite-like carbon films synthesized by magnetron sputtering. Surf. Coat. Technol. 2010, 205, 793-800. [CrossRef] 
5. Huang, J.; Wang, L.; Liu, B.; Wan, S.; Xue, Q. In Vitro Evaluation of the Tribological Response of Mo-Doped Graphite-like Carbon Film in Different Biological Media. ACS Appl. Mater. Interfaces 2015, 7, 2772-2783. [CrossRef] [PubMed]

6. Wang, Y.; Li, H.; Ji, L.; Liu, X.; Wu, Y.; Lv, Y.; Fu, Y.; Zhou, H.; Chen, J. Synthesis and characterization of titanium-containing graphite-like carbon films with low internal stress and superior tribological properties. J. Phys. D Appl. Phys. 2012, 45, 556-563. [CrossRef]

7. Zhang, S.; Bui, X.L.; Fu, Y. Magnetron-sputtered nc-TiC/a-C(Al) tough nanocomposite coatings. Thin Solid Film. 2004, 467, 261-266. [CrossRef]

8. Voevodin, A.A.; Zabinski, J.S. Nanocomposite and nanostructured tribological materials for space applications. Compos. Sci. Technol. 2005, 65, 741-748. [CrossRef]

9. Wang, Y.; Pu, J.; Wang, J.; Li, J.; Chen, J.; Xue, Q. Interlayer design for the graphite-like carbon film with high load-bearing capacity under sliding-friction condition in water. Appl. Surf. Sci. 2014, 311, 816-824. [CrossRef]

10. Li, L.; Guo, P.; Liu, L.-L.; Li, X.; Ke, P.; Wang, A. Structural design of Cr/GLC films for high tribological performance in artificial seawater: Cr/GLC ratio and multilayer structure. J. Mater. Sci. Technol. 2018, 34, 1273-1280. [CrossRef]

11. Strondl, C.; Carvalho, N.M.; De Hosson, J.T.M.; van der Kolk, G.J. Investigation on the formation of tungsten carbide in tungsten-containing diamond like carbon coatings. Surf. Coat. Technol. 2003, 162, 288-293. [CrossRef]

12. Dwivedi, N.; Kumar, S.; Malik, H.K. Nanostructured Titanium/Diamond-Like Carbon Multilayer Films: Deposition, Characterization, and Applications. ACS Appl. Mater. Interfaces 2011, 3, 4268-4278. [CrossRef]

13. Wang, J.; Pu, J.; Zhang, G.; Wang, L. Interface Architecture for Superthick Carbon-Based Films toward Low Internal Stress and Ultrahigh Load-Bearing Capacity. ACS Appl. Mater. Interfaces 2013, 5, 5015-5024. [CrossRef] [PubMed]

14. Gong, D.; Xu, F. Study on the microstructure and mechanical properties of graphite like carbon films incorporated with Cu. Diam. Relat. Mater. 2019, 100, 107549. [CrossRef]

15. Wang, W.; Ji, L.; Li, H.; Liu, X.; Zhou, H.; Chen, J. Influence of rotational speed on structure, mechanical and electrical properties of TiC/GLC composite films. Diam. Relat. Mater. 2019, 92, 65-73. [CrossRef]

16. Stueber, M.; Albers, U.; Leiste, H.; Ulrich, S.; Holleck, H.; Barna, P.B.; Gee, I. Multifunctional nanolaminated PVD coatings in the system Ti-Al-N-C by combination of metastable fcc phases and nanocomposite microstructures. Surf. Coat. Technol. 2006, 200, 6162-6171. [CrossRef]

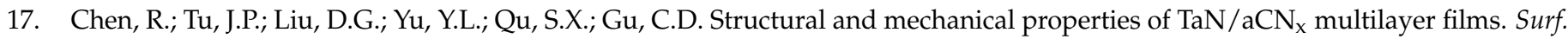
Coat. Technol. 2011, 206, 2242-2248. [CrossRef]

18. Liu, D.G.; Tu, J.P.; Zhang, H.; Chen, R.; Gu, C.D. Microstructure and mechanical properties of carbon nitride multilayer films deposited by DC magnetron sputtering. Surf. Coat. Technol. 2011, 205, 3080-3086. [CrossRef]

19. Wang, W.; Ji, L.; Li, H.; Zhou, H.; Chen, J. Self-organized formation of nano-multilayer structure in the carbon-copper thin film during reactive magnetron sputtering deposition process. J. Alloys Compd. 2017, 722, 242-249. [CrossRef]

20. Wu, W.-Y.; Ting, J.-M. Growth and characteristics of metal-containing diamond-like carbon using a self-assembled process. Carbon 2006, 44, 1210-1217. [CrossRef]

21. Wu, Y.; Li, H.; Ji, L.; Ye, Y.; Chen, J.; Zhou, H. A long-lifetime $\mathrm{MoS}_{2}$ /a-C:H nanoscale multilayer film with extremely low internal stress. Surf. Coat. Technol. 2013, 236, 438-443. [CrossRef]

22. Scandurra, R.; Scotto d'Abusco, A.; Longo, G. A Review of the Effect of a Nanostructured Thin Film Formed by Titanium Carbide and Titanium Oxides Clustered around Carbon in Graphitic Form on Osseointegration. Nanomaterials 2020, 10, 1233. [CrossRef]

23. Tsai, P.-C.; Hwang, Y.-F.; Chiang, J.-Y.; Chen, W.-J. The effects of deposition parameters on the structure and properties of titanium-containing DLC films synthesized by cathodic arc plasma evaporation. Surf. Coat. Technol. 2008, 202, $5350-5355$. [CrossRef]

24. Sridhar, N.; Rickman, J.M.; Srolovitz, D.J. Multilayer film stability. J. Appl. Phys. 1997, 82, 4852-4859. [CrossRef]

25. Li, F.; Zhang, S.; Kong, J.; Zhang, Y.; Zhang, W. Multilayer DLC coatings via alternating bias during magnetron sputtering. Thin Solid Film. 2011, 519, 4910-4916. [CrossRef]

26. Choy, K.-L.; Felix, E. Functionally graded diamond-like carbon coatings on metallic substrates. Mater. Sci. Eng. A 2000, 278, 162-169. [CrossRef]

27. Alawajji, R.A.; Kannarpady, G.K.; Nima, Z.A.; Kelly, N.; Watanabe, F.; Biris, A.S. Electrical properties of multilayer (DLC-TiC) films produced by pulsed laser deposition. Appl. Surf. Sci. 2018, 437, 429-440. [CrossRef]

28. Rose, F.; Wang, N.; Smith, R.; Xiao, Q.-F.; Inaba, H.; Matsumura, T.; Saito, Y.; Matsumoto, H.; Dai, Q.; Marchon, B.; et al. Complete characterization by Raman spectroscopy of the structural properties of thin hydrogenated diamond-like carbon films exposed to rapid thermal annealing. J. Appl. Phys. 2014, 116, 123516. [CrossRef]

29. Fogarassy, Z.; Oláh, N.; Cora, I.; Horváth, Z.; Csanádi, T.; Sulyok, A.; Balázsi, K. The structural and mechanical characterization of $\mathrm{TiC}$ and $\mathrm{TiC} / \mathrm{Ti}$ thin films grown by DC magnetron sputtering. J. Eur. Ceram. Soc. 2018, 38, 2886-2892. [CrossRef]

30. Wang, Y.; Wang, L.; Wang, S.C.; Zhang, G.; Wood, R.; Xue, Q. Nanocomposite Microstructure and Environment Self-Adapted Tribological Properties of Highly Hard Graphite-Like Film. Tribol. Lett. 2010, 40, 301-310. [CrossRef]

31. Song, H.; Ji, L.; Li, H.; Liu, X.; Wang, W.; Zhou, H.; Chen, J. External-Field-Induced Growth Effect of an a-C:H Film for Manipulating Its Medium-Range Nanostructures and Properties. ACS Appl. Mater. Interfaces 2016, 8, 6639-6645. [CrossRef] [PubMed] 
32. Bai, W.Q.; Li, L.L.; Wang, X.L.; He, F.F.; Liu, D.G.; Jin, G.; Tu, J.P. Effects of Ti content on microstructure, mechanical and tribological properties of Ti-doped amorphous carbon multilayer films. Surf. Coat. Technol. 2015, 266, 70-78. [CrossRef]

33. Leyland, A.; Matthews, A. On the significance of the H/E ratio in wear control: A nanocomposite coating approach to optimised tribological behaviour. Wear 2000, 246, 1-11. [CrossRef] 